\title{
O Exercício Cotidiano do Agente de Saúde na Unidade de Saúde da Família - Capela de São Bráz
}

Cícera Alencar da Silva ${ }^{1}$; Daniella dos Santos Souza²; Jadeane Cardoso Lima ${ }^{3}$; Lucimara Araújo Campos Alexandre ${ }^{4}$

\begin{abstract}
Resumo: O presente trabalho tem como objetivo analisar as produções científicas sobre o Agente Comunitário de Saúde (ACS) e as funções e atividades concernentes à comunidade, in loco. O delineamento metodológico do estudo é realizado através de pesquisa de campo, a qual através de uma entrevista e visita à USF - Unidade de Saúde da Família, no município de Ouricuri - PE, os ACS - denominados, Mandacaru, Facheiro e Coroa de Frade demonstram total disponibilidade, responsabilidade e uma relação interpessoal que facilita a principal ação - de ser o elo entre a comunidade e o Sistema Único de Saúde. Para tanto, o ACS deve obrigatoriamente residir na comunidade no sentido do fortalecimento de vínculo e, assim, poder exercer seu papel de oferecer o melhor e mais efetivo atendimento à saúde da comunidade, inclusive produzindo junto à mesma uma melhoria na qualidade de vida da população do bairro.
\end{abstract}

Palavras Chave: Agentes Comunitários de Saúde. Comunidade. Saúde.

\section{The Everyday Exercise of the Health Agent in the Family Health Unit - São Braz Chapel}

\begin{abstract}
The present work aims to analyze the scientific productions about the Community Health Agent (CHA) and the functions and activities concerning the community, in loco. The methodological delineation of the study is through field survey, which through an interview and visit to the USF - Family Health Unit, in the municipality of Ouricuri - PE, the ACS - called, Mandacaru, Facheiro and Coroa Frade demonstrat their total availability, responsibility and An interpersonal relationship that facilitates its main action - to be the link between the community and the Unified Health System. For this, the ACS must reside in the community in order to strengthen the bond and thus be able to exercise its role of offering The best and most effective health care of the community, including producing along with it an improvement in the quality of life of the population of the neighborhood.
\end{abstract}

Keywords: Communities Health Agents. Community. Health.

\section{Introdução}

Em 1991 criou-se, no Brasil, o Programa de Agentes Comunitários de Saúde (PACS), cujas normas e diretrizes só foram aprovadas pela portaria $\mathrm{N}^{\circ} 1.886 / 97$ (BRASIL, 1997), no contexto, a profissão de - Agente Comunitário de Saúde - ACS - necessitava ser regulamentada e o foi em 2002, com a promulgação da lei $N^{\circ}$ 10.507/2002 (BRASIL, 2002).

\footnotetext{
${ }^{1}$ Graduanda em administração Pública pela Universidade Federal do Vale do São Francisco;

${ }^{2}$ Graduanda em administração Pública pela Universidade Federal do Vale do São Francisco;

${ }^{3}$ Graduanda em administração Pública pela Universidade Federal do Vale do São Francisco. Contato: jadeanecl13@ @otmail.com;

${ }^{4}$ UNIVASF - Universidade Federal do Vale do São Francisco. Professor da Pós Graduação em Gestão Pública - UNIVASF.

Contato: lucimara.univasg@gmail.com.
} 
Para tanto, o Ministério da Saúde tratou de efetivar e assegurar os princípios e diretrizes do Sistema Único de Saúde-SUS, no sentido de serem utilizados em prol da saúde da família. Assim, constituíram-se as USF - Unidades de Saúde da Família que fazem parte de uma rede universal de saúde que busca equidade no atendimento em parceria com o governo em suas esferas, com foco na população mais carente. Sua organização se dá a partir de uma Equipe de Saúde da Família (ESF), multiprofissional, a qual é composta, normalmente, por um médico generalista, enfermeiro especialista em saúde da família, auxiliar ou técnico de enfermagem, agentes comunitários de saúde (ACS), um odontólogo cirurgião-dentista generalista e um auxiliar em Saúde Bucal. Esses membros devem conhecer muito bem a comunidade em que atuam, dentre eles, o ACS, é aquele profissional que representa a comunidade no serviço de saúde. Para tanto é o profissional - ou seja, é fundamental para envolver a população no enfretamento dos problemas relacionados à saúde e à melhoria da qualidade de vida, por isso o ACS em sua rotina de trabalho deve responsabilizar-se por um máximo de 750 pessoas, e de 12 ACS por equipe de Saúde da Família, não ultrapassando o limite máximo recomendado de pessoas por equipe, segundo regulamentação do Ministério da Saúde. (BRASIL, 2012)

De fato, surgiu como um novo modelo de atenção à saúde com a função de atuar para a melhoria da saúde materno-infantil e o combate de doenças como diarreia e pneumonia. Atualmente, a profissão de ACS é bastante pesquisada pelas universidades em nosso país, pois circula tanto no âmbito governamental quanto em meio à comunidade, servindo de elo entre as duas instâncias. (BRASIL. 2017).

É importante destacar que com as mudanças nas necessidades das comunidades, como por exemplo, as mortes, atualmente, são causadas mais por derrames, infartos, anginas e algumas outras doenças não infecciosas, portanto o agente de saúde não mais se preocupa apenas com doenças transmissíveis, mas com as não transmissíveis, também.

\section{A comunidade e o agente de saúde}

A Unidade de Saúde da Família - USF, juntamente com o ACS, no dever de suas atribuições, além de realizar o cadastramento das famílias, deve manter esse cadastro sempre 
atualizado e estarem atentos e identificar as áreas que ele deve acompanhar, por meio da visita domiciliar mensalmente, todas as famílias da sua área de atuação. E também, desenvolver ações de educação e vigilância à saúde. Nesse âmbito, trabalha com a mobilização comunitária, contando com o apoio da Secretaria Municipal de Saúde para cumprir uma demanda preocupante do Ministério da Saúde(MS) de fazer do ACS um fomentador do uso correto de medicamentos, dirimindo a auto-medicação que tantos problemas têm causado as pessoas. (SILVA et, 2005)

Assim, o trabalho do ACS junto à comunidade consiste em oportunizar que diversas informações cheguem com mais rapidez e qualidade. As famílias que são assistidas, em sua maioria são carentes não apenas de informação, mas da qualidade dessas para que possa evitar novos problemas e, com essa oportunidade a qualidade de vida tende a melhorar o que decerto influenciará numa melhoria em outros aspectos, como na prestação de cuidados primários de saúde e a concretização da municipalização pelo MS.

Para tanto se faz necessário registros, mapas de localização que demonstrem as áreas que precisam de mais atenção, como por exemplo, as que não possuem tratamento de esgoto, a precariedade no abastecimento de água, dentre outros problemas, os quais causam danos à saúde física e/ou mental das pessoas, faz-se necessário buscar medidas cabíveis para o bem estar da comunidade através do planejamento e da tomada de decisões do Agente de Saúde. O profissional observa os riscos, a vulnerabilidade, a resiliência, o imperativo ético de toda a demanda e acolhe cada membro da comunidade. (BRASIL,2012)

O trabalho do ACS é muito diferenciado dos demais profissionais da saúde porque ele se envolve em questões acerca de doença x saúde; prevenção $\mathrm{x}$ assistência e educação $\mathrm{x}$ informação, num contato constante, próximo com a comunidade, como também, dá orientações voltadas para o meio ambiente, saneamento básico, primeiros socorros; grande parte dos atendimentos acontecem nas chamadas 'visitas domiciliares'(grifo nosso), quando é possível identificar se existem pessoas que necessitam de cuidados especiais, tais como, gestante, idosos, crianças, deficientes mentais, dentre outros. Dependendo dessas informações, a quantidade de visitas deve ser alterada para o bem estar dos assistidos.

Nesse contexto, o fortalecimento da saúde passa pela ação do ACS, um profissional ideal para integrar os serviços de saúde de atenção primária à comunidade. O Ministério da Saúde sabe que esse profissional precisa ser qualificado e passar por formação continuada, no 
âmbito do seu trabalho, e, por isso, leva publicações para informá-lo em relação a assuntos que lhe diz respeito, de forma atualizada. Para tanto, se pode citar o "Guia Prático do Agente Comunitário de Saúde, elaborado pelo Departamento de Atenção Básica, cujo tem como objetivo oferecer subsídios para o desenvolvimento do trabalho do ACS.” (BRASIL, 2017, p.9)

\section{O Agente Comunitário de Saúde de Ouricuri-PE}

Para integrar a área de ACS em Ouricuri-Pe foram determinadas algumas peculiaridades, como: Idade mínima de 18 anos, residirem na área de atuação no mínimo 02 anos, e cumprir carga horária de oito horas diárias, além de ter concluído o $1^{\circ}$ grau. Em 2016 foi realizado um concurso nesta área, em seguida, os aprovados participaram de um curso introdutório com submissão de exame escrito, por conseguinte, foram entrevistados individualmente, para ser selecionado um ACS para cada microárea.

Durante uma conversa informal com um ACS, chamado Mandacaru, este diz que o último concurso, do qual participou, foi o primeiro no município porque antes só havia contratação de pessoas para exercerem a mesma função. Geralmente, esses ACS trabalhavam cerca de quatro anos, uma administração inteira. Esta permanência se devia à influência político-partidária na forma de contratação. Agora, gerou-se uma nova expectativa, que os profissionais permaneçam por bastante tempo, até que se aposentem, gerando uma estabilidade nas equipes e a possibilidade de manter a continuidade, sem idas e vindas, no processo de trabalho.

De acordo com a informação do ACS entrevistado, foi promovida Formação Continuada, com cursos elaborados pela Secretária Municipal de Saúde, sendo distinguido em duas fases, com finalidade de transmitir conhecimento geral, específicos e psicológicos, almejando construir uma experiência sólida.

Segundo a Enfermeira, Secretária de Saúde, esses agentes continuarão em um programa de educação continuada, elaborado pelo próprio município, quando a cada bimestre serão ministrados conteúdos relevantes e necessários à prática cotidiana dos ACS. O conteúdo do Curso será ministrado por uma equipe multiprofissional, formada de técnicos do próprio 
município, para todos os componentes das equipes e contemplará os seguintes temas, dentre eles: Trabalho em equipe, Atenção primária à saúde, Diagnóstico de saúde da comunidade, Planejamento estratégico e participação social, Programas Prioritários e Supervisão e avaliação. Quanto ao conteúdo dos temas da educação continuada, podemos observar a predominância de assuntos relacionados ao cuidado individual e as doenças, o que contradiz a própria concepção da estratégia da Saúde da Família, do trabalho coletivo e de ações voltadas para a promoção da saúde e a prevenção de agravos, sem desconsiderar que a doença existe (SILVA, 2012). A secretária recebeu os pesquisadores para uma conversa informal, pois segundo a mesma "o tempo está exíguo para entrevista, pois acabei de assumir a pasta."

\section{Ações desenvolvidas pelo ACS no cotidiano da USF}

Os ACS - Mandacaru, Facheiro, Coroa de frade, da equipe do PSF, São Braz, de Ouricuri-PE, quando suscitados a participarem de uma entrevista semi-estruturada, concordaram sem impor nenhuma dificuldade. São apenas três que trabalham na área, por ser um bairro com menos de 1.200 habitantes.

Ambos desenvolvem um amplo leque de ações, algumas estabelecidas de acordo com suas capacidades para exercê-las e dentro do proposto pelo Ministério da Saúde, outras fora dos seus âmbitos de ação, pois dizem respeito ao exercício de outros profissionais. O processo de trabalho das equipes é bastante diversificado, mas no geral, eles executam diversas atividades. Nas burocráticas está o planejamento das ações, registros e consolidação dos dados, cadastramentos e reuniões de equipe.

As ações de Vigilância à saúde, têm na visita domiciliar um instrumento para sua efetivação, uma vez que é por meio desta que vão conhecer a população de sua área de abrangência e perceber os riscos à saúde das famílias das áreas de atuação (MENDES, 2013).

No acompanhamento de hipertensos, diabéticos, gestantes, crianças de zero a cinco anos, acamados, parturientes e, recém-nascidos, mulheres, ou seja, dos grupos considerados de risco, eles orientam o autocuidado e a prevenção de agravos à saúde. Durante a visita, segundo Mandacaru, "devemos verificar o ambiente domiciliar no sentido de orientar sobre a higiene, evitando, assim, a presença do mosquito da dengue e a verminose". 
Em relação à educação para a saúde, Facheiro disse que "é realizada por meio de orientações individuais aos grupos de risco, para promovermos a participação das famílias em palestras na comunidade".

Quando se perguntou sobre as ações que consideram mais importante, os três ACS citaram "as visitas a pessoas doentes". Para os três, essas visitas são imprescindíveis, e podemos acrescentar, como exemplo, os agendamentos de consultas, preventivo, aviso de reuniões a hipertensos, diabéticos, gestantes, mulheres, informações sobre o funcionamento da unidade de Saúde da Família, além da agilização da entrega e solicitações de exames, entrega de medicamentos, às vezes multimistura e acompanhamento para especialista (LEFÉVRE et al.,2012). E, com o mesmo fim de aproximar a comunidade do serviço de saúde, tendo em vista o acompanhamento das famílias e a melhoria das condições de vida, deve articular junto à comunidade a participação nas Associações Comunitárias e nos Conselhos Locais de Saúde. (IBDEM).

\section{Método e resultados}

Os procedimentos metodológicos utilizados para a elaboração deste trabalho se fundamentou por meio de consultas através de leituras em diversos livros e revistas em que os vários autores falam da temática de forma bastante clara e objetiva, especificando os aspectos do trabalho dos Agentes de Saúde da Família.. Segundo Andrade (2001, p. 121), "pesquisa é o conjunto de procedimentos sistemáticos, baseados no raciocínio lógico, que tem por objetivo encontrar soluções para problemas propostos, mediante a utilização de métodos científicos. "

Em relação à pesquisa realizada, a entrevista semi-estruturada é o método escolhido para a coleta de dados acerca dos ACS, da USF - do bairro - Capela de São Braz, em cujo há cerca de 1.100 pessoas que fazem parte da comunidade. A referida entrevista traz a realidade cotidiana desses profissionais, concursados, há menos de um ano.

À procura de se saber acerca da comunidade, o ACS - Coroa de Frade, como denominado, relata que possui muitos idosos e muitas crianças, mas são pessoas acessíveis, que participam da associação de moradores, porém ele se refere a uma certa acomodação das pessoas em lutar pelos direitos, já conquistados. 
Quando se indaga sobre o porquê da afirmação anterior, ele reforça a ideia de que "a pessoa acostuma-se a viver de qualquer forma, com o esgoto passando a céu aberto, com animais soltos nas ruas e se não tiver protagonista, na comunidade, para incentivar e até buscar sanar alguns problemas, tudo acaba ficando como está”.( FACHEIRO,2017)

Com efeito, Mandacaru, responde a respeito das suas atribuições diárias, na USF, em destaque -“ desenvolvemos atribuições inerentes as necessidades das famílias, desse bairro"; Mandacaru, ressalta que "tudo se desenvolve dentro de uma organização de trabalho e uma formação adequada ,favorecendo o fortalecimento de uma atenção básica, junto as famílias”.

Em relação à interlocução entre ACS e usuários, Facheiro destaca o vínculo comunicativo que predomina, considerando significativo, por se identificar com a população, e estimular a enfrentar os problemas acarretados na saúde básica, buscando sempre melhoria nos serviços fornecidos. Ainda, nesse âmbito, Coroa de Frade, acredita que "é fundamental este vínculo para o desempenho das nossas atividades e para que o programa possa atingir os seus objetivos em relação a uma melhor qualidade de vida na comunidade".

Com relação à frequência de usuários cadastrados na Unidade de Saúde da Família, Mandacaru responde que "procuramos manter um acompanhamento regular, pois as famílias cadastradas precisam de atenção contínua de cada um de nós", ou seja, os próprios ACS cadastraram os usuários, as famílias de responsabilidade da USF. Os ACS desenvolvem suas atribuições, com conhecimento de causa, pois, conforme Correia e Nascimento (2008) o cadastramento das famílias é realizado exclusivamente pelos agentes comunitários de saúde de casa em casa. Para o Ministério da Saúde o ACS deve saber quais são os problemas de saúde a serem sanados junto à população sob sua responsabilidade, organizando-as em relação aos outros pontos de atenção, contribuindo para que a programação dos serviços de saúde parta das necessidades de saúde dos usuários. (MS,2012).

Quando a pergunta é voltada para a quantidade de visitas domiciliares, realizadas por cada um deles, os três são unânimes em afirmar que " depende, geralmente é 01 ou 02 visitas no mês, mas, quando há necessidade são duas, três, quantas vezes forem necessárias. É de acordo com a demanda.(MANDACARU, FACHEIRO, COROA DE FRADE,2017).

E, de fato, pela atenção dada a essa pesquisa, os ACS mostraram-se bastante responsáveis com a profissão que abraçaram e se mostram abertos a atenderem com muito cuidado as demandas que surgirem. Isso representa um avanço para o Ministério da Saúde, no 
sentido do aumento da capacidade de análise, intervenção e autonomia que corroboram para práticas transformadoras e o estreitamento entre o que é concepção de trabalho e execução.(MS,2012)

Ao indagar-se o que eles têm a ressaltar em relação ao serviço de saúde na USF, aonde trabalham, eles responderam "é fato que o país precisa mudar a atenção que é dada à saúde e o ACS é um modelo de cuidado que deve continuar em crescimento porque faz a diferença na comunidade, se tiver o respaldo, junto as pessoas e aos demais pares, no sentido de que a saúde precisa ser mais humanizada, mais educada em alguns setores ou os trabalhadores da saúde precisam ser mais lapidados em relação à educação ao receber pessoas doentes, porque muitas vezes - o doente está mais carente de atenção. (MANDACARU,FACHEIRO, COROA DE FRADE, 2017)

Nesse contexto, ao se avaliar o resultado obtido, verifica-se a grande contribuição do Agente de Saúde da Família e sua importância diante das atribuições que lhes são inerentes, principalmente, a visita domiciliar, uma das principais atividades desenvolvida pelos ACS, pois a partir delas, os profissionais têm a possibilidade de melhor conhecer as necessidades das famílias e, principalmente, desenvolver o trabalho educativo. Mas para que as visitas domiciliares não se tornem atividades pouco resolutivas, faz-se necessário organizá-las, respaldados em critérios, como por exemplo, área de risco (vulnerabilidade). Isto quer dizer que esse contato efetivo dos ACS no desenvolvimento de ações educativas com as famílias estabelece um comprometimento com a saúde, estimulando hábitos saudáveis, a fim de desenvolver informações cabíveis sobre as descrições e características das doenças.

No que diz respeito à capacidade de comunicação, o ACS, Facheiro reforça que "procuramos chegar com as informações com uma linguagem clara e importante para o cotidiano, pois os usuários veem em nós uma pessoa da família deles”. Demonstrando a sua preocupação maior de querer "vê a comunidade levando a sério toda informação que amenize as dificuldades seja de saúde, em relação ao ambiente, dentre outros.(FACHEIRO,2017)

Os resultados sugerem que os ACS ao atenderem, com qualidade o morador do bairro de atuação, têm por finalidade, aumentar a eficácia das ações educativas, uma vez que essas pessoas compartilham uma mesma realidade social, cultural e um mesmo universo, possibilitando utilizar as ações. 
Em relação à remuneração desses profissionais, os mesmos respondem que "o município faz o pagamento rigorosamente em dias, pois a verba, do Ministério da Saúde, já vem destinada para esse fim e, conforme Coroa de Frade, após a nova administração municipal, as condições do bairro tem mudado - já está sendo realizado o saneamento de algumas ruas, o calçamento, melhorando a qualidade de vida da comunidade".

Assim, a entrevista, tornou-se um momento prazeroso, pois os três ACS ficaram juntos e cada um fez questão de ajudar um ao outro e, de fato, representa o evento discursivo em que entrevistadores e entrevistados marcaram expectativas que circulam no momento de realização da mesma, assim como na escuta e na análise do produto coletado.

De modo que os ACS entrevistados têm perfis adequados para a função. Portanto, eles possuem as competências requeridas: iniciativa, responsabilidade, autonomia, inteligência prática, capacidade de coordenar-se com outros atores e situações e acontecimentos próprios de um campo profissional. Assim, ele deve ter as habilidades de saber fazer, conhecer, ser e conviver com os outros (BRASIL, 2016).

Em relação às dificuldades, o ACS Mandacaru menciona o termo teimosia da comunidade, enquanto Coroa de Frade e Facheiro mencionam "a displicência com que a comunidade trata questões tão debatidas em palestras educativas, em reuniões da associação de moradores e até na escola - o acúmulo de lixo nos quintais - latas, caixas inutilizadas que ficam atraindo ratos e baratas e outros animais; a questão das crianças brincando nas ruas, descalças; as que vão para a aula sem tomar banho, sem escovar os dentes porque acordam, muitas vezes em cima da hora de chegar à escola" e, Mandacaru diz haver um outro problema muito marcante para nós "o dos esgotos, mas, graças à associação de moradores, enfim o poder público está tomando as providências cabíveis, e os pernilongos estão diminuindo, o mau cheiro que havia, também.(MANDACARU,2017).

De modo que são dificuldades muito comuns na comunidade. Talvez a cultura a impeça de coibir práticas danosas à saúde das crianças e da própria comunidade como um todo.

No que diz respeito às doenças mais encontradas no bairro, os ACS citam hipertensão, diabetes, artrite, hérnia de disco, problemas neurológicos, dia. Isso demonstra que o trabalho educativo deve ser intensificado, no sentido de que a comunidade evite as chamadas, práticas danosas, do cotidiano, e insistir que a comunidade precisa melhorar a qualidade de vida. 


\section{Considerações finais}

Diante dessa pesquisa observa-se a importância do ACS para efetivação e continuidade das ações de saúde, pois se trata de um trabalho que impulsiona a população para a porta de entrada do serviço de saúde, a Estratégia de Saúde da Família (ESF).

Observa-se que além das atividades atribuídas comumente a esta categoria profissional, identifica-se uma relação de confiança com a comunidade ao se observar o fortalecimento de ações das demais políticas sociais, pois é através desse elo com as famílias que os ACS podem identificar outras situações que demandam atuação da política de assistência social, de educação e até mesmo judicial.

Para um bom trabalho, os ACS, devem acompanhar uma comunidade da periferia e nela tentar fazer a diferença, através da educação, da linguagem, dos instrumentos que aprendeu a usar para diminuir os problemas existentes, mesmo diante das dificuldades.

O estudo mostra, que os ACS, da USF, em estudo, têm uma comunicação interpessoal bem resolvida com a comunidade e prazer em incorporar a competência para agir em três dimensões - técnica, assistência e política, no agir coletivamente ou individualmente.

Os ACS sabem que devem ser, acima de tudo, profissionais com uma visão macro para contribuir na efetivação das políticas públicas de saúde para as famílias que, muitas vezes, estão marginalizadas. Isto quer dizer que os ACS têm que se lembrar, a todo o momento, que o ponto de partida do trabalho deles é a interlocução entre a Equipe de Saúde da Família-ESF e a população.

É nítido que não pretendemos com esse artigo esgotar a discussão sobre as pesquisas realizadas com Agentes Comunitários de Saúde, mas contribuir para iniciar uma discussão sobre esse grupo como objeto de pesquisa e as formas adotadas até então pelos pesquisadores a fim de obter dados e quem sabe, um leitor da nossa pesquisa, deseje ser um ACS e fazer parte da vida da comunidade, desenvolvendo as habilidades concernentes a esse profissional e poder num trabalho de política de saúde, refletir e transformar os entraves existentes na efetivação dos direitos garantidos no Sistema Único de Saúde (SUS). 


\section{Referências}

BRASIL. Ministério da Saúde (BR). Guia prático do Programa de Saúde da Família. Brasília (DF): 2001.128p.

BRASIL. MINISTÉRIO DA SAÚDE. SECRETARIA EXECUTIVA. Programa de agentes comunitários de saúde (PACS). Brasília, 2001.

Ministério da Saúde (BR). Monitoramento da implantação e funcionamento das equipes de saúde da família no Brasil. Brasília (DF): 2002.82p.

. Lei n ${ }^{\circ}$ 10.507, de 10 de julho de 2002. Cria a Profissão de Agente Comunitário de Saúde e dá outras providências. Diário Oficial da Republica Federativa do Brasil, Brasília, 11 jul. 2002.

Estatuto da Criança e do Adolescente- Lei no 8.069, de 13/7/1990. Disponível em: http://www.pklanalto.gov.brAcesso em 10/03/2017

BRASIL. Ministério da Saúde. Política Nacional de Atenção Básica Secretaria de Atenção à Saúde. Departamento de Atenção Básica. - Brasília: Ministério da Saúde, 2012.

Ministério da Saúde. Guia prático do agente comunitário de saúde. Secretaria de Atenção à Saúde, Departamento de Atenção Básica. - Brasília: Ministério da Saúde, 2016.

CORREA, C. R. S; NASCIMENTO, E. P. L. O Agente comunitário de saúde: formação inserção e práticas. Cad. Saúde Pública, Rio de Janeiro, v. 24, n. 6, p. 1304-1313, 2008.

LEFÉVRE F, LEFRÉVE AMC. O Discurso do Sujeito coletivo: uma nova abordagem metodológica em pesquisa qualitativa. São Paulo: EDUCS; 2012.

MENDES EV. Uma Agenda para a Saúde. $2^{a}$ ed. São Paulo: Hucitec UCITEC; 2009.300 p.

MENDES EV. A Atenção Primária à Saúde no SUS. Fortaleza (CE): Escola de Saúde Pública do Ceará; 2013.

http://www.opas.org.br/medicamentos/docs/HSE_ASF_REM_1205.pdfAcesso em:08 fev. 2017.

http://www.planalto.gov.br/ccivil/LEIS/L8069.htm Acesso em: 25/03/ 2017.

http://www.guiaacs.gov.br/htm Acesso em: 20 fev. 2017.

Como citar este artigo (Formato ABNT):

SILVA, Cícera A.; SOUZA, Daniella dos S.; LIMA, Jadeane C.; ALEXANDRE, Lucimara A.C. O Exercício cotidiano do Agente de Saúde na Unidade Saúde da Família - Capela de São Bráz . Id on Line Revista Multidisciplinar e de Psicologia, 2017, vol.11, n.37, p.132-142. ISSN: 1981-1179.

Recebido: 09.08.2017;

Aceito: 11.08 .2017 